\title{
The joys of spinelessness
}

\section{Lisa-ann Gershwin delights in two books on marine invertebrates.}

I was love at first sight. On 21 January 1973, I saw my first octopus at Cabrillo Marine Aquarium in Los Angeles, California. I was almost nine, and totally smitten. Almost 20 years later, at the very same place, jellyfish stole my affection.

The popular-science gods don't normally smile on those of us with an interest in 'the other 99\%' of animals - invertebrates. Now, two new books on them have surfaced at once: Spineless by science writer Juli Berwald and Squid Empire by marine scientist and communicator Danna Staaf. Both authors are passionate, articulate and fascinated by their subjects.

Jellies have no heart, blood or brain, and yet have persisted unchanged while others around them have come and gone, evolved gills, calcified bones, grown legs and learnt to fly. Cephalopods, by contrast, can use tools, solve puzzles and open jars to access prey, and their extraordinary physical flexibility lets them mimic shapes and ooze through tiny holes. Despite their differences, both are emerging as winners in changing seas.

With all due respect to those studying corpulent gastropods or the hook-faced worms called chaetognaths, it is often said that scientists come to resemble the creatures they study. With Berwald and Staaf, the resemblance is in writing style. Spineless feels planktonic, drifting through the depth and breadth of research into jellyfish swarms, or blooms. Squid Empire feels more 'nektonic', or free-swimming: a fast-paced and confident approach to cephalopods. Together, they offer a splendid backstory for the blobs dotting beaches and the multi-armed cephalopods in public aquaria (or calamari on a plate).

Spineless is part travelogue, part self-discovery and part research. Berwald takes us on a leisurely journey from her years as a graduate student, through juggling textbook writing and motherhood, to travelling the world to meet the human and gelatinous players in the field of jellyfish blooms. On a Japanese island to see the famed giant jellyfish Nemopilema nomurai, she feels fascinated but empty as she watches them melt away once out of the sea.

We learn what dozens of jellyfish experts think, and how Berwald's feelings evolve, flipping back and forth between technical and emotive. ("Perhaps jellyfish strike an unconscious nerve, far below what we are still certain we know, of a past before violence, before consumption, before aggression.") The result is delightful; but the book has some shortcomings, including technical

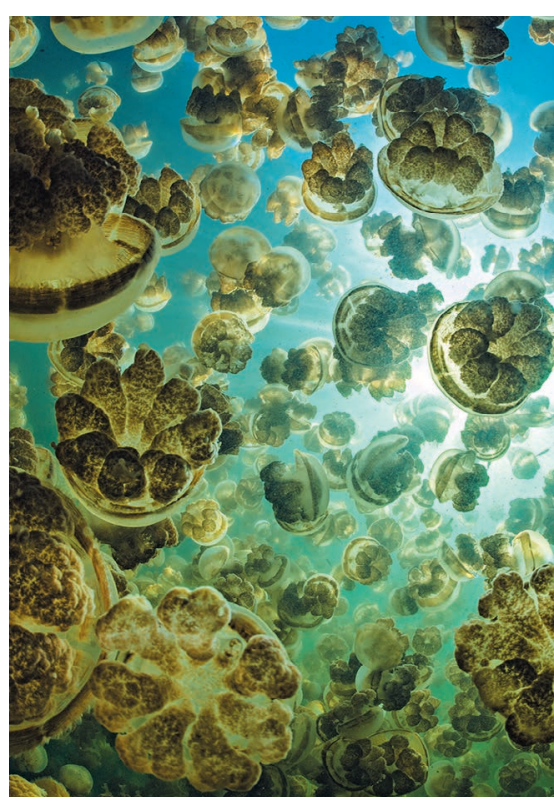

Golden jellyfish (Mastigias sp.) in Palau.

errors (incorrect species names and syntax referring to life stages) and inconsistent language that may confuse non-scientific readers. Importantly, it never mentions Claudia Mills, whose 1995 paper on jellyfish blooms launched the field (C. E. Mills ICES J. Mar. Sci. 52, 575-581; 1995). I also found the mention of commercial products (such as controversial sting blockers) intrusive, and details of her feelings about jellyfish eminence Monty Graham and a surfing former boyfriend seemed too personal.

Anyone beguiled by dinosaurs will probably find Squid Empire irresistible. Staaf compares how both the "terrible lizards" and the "head-footed" cephalopods evolved, diversified and ate their way through their ancestors, then mostly perished in the hostile conditions at the end of the Cretaceous period, 66 million years ago. Through her words, we learn how evolution of a buoyant shell gave ammonites, nautiluses and their early kin the ability to rise off the sea floor and become fearsome predators, only to find themselves prey to jawed fish. And so began an arms race

Spineless: The Science of Jellyfish and the Art of Growing a Backbone

JULI BERWALD

Riverhead: 2017.

Squid Empire: The Rise and Fall of the

Cephalopods

DANNA STAAF

ForeEdge: 2017. between the shelled krakens and the bony upstarts: fish evolved teeth to crack the shells of their prey, while those prey thickened their protective shells. In this adapt-or-die world, the crucial innovation proved to be jet propulsion. That seems to have evolved as a consequence of cephalopods in the Cambrian period (541 million to 485 million years ago) jerking their bodies back into the shell and thus expelling water. It was gradually refined into the sleek locomotion we know today.

A sucker for cephalopods, Staaf expertly interprets the fossil record, marvelling at disturbingly stretchy arms, a live-fast-dieyoung strategy and the paradox of ammonia. (Ammonia sequestered in squid tissues gives them buoyancy, but it makes their $\mathrm{pH}$ too high for fossilization; thus, the squid's major evolutionary advantage keeps it out of the fossil record.) We come to appreciate squid, octopuses and cuttlefish as clever survivors.

Staaf's approach is short and sweet, well illustrated and strong on playful narrative. (Invoking the whodunnit board game Cluedo, she writes: "There's no envelope we can open to check our theory of the ammonoids' extinction by Mr. Asteroid in the Cretaceous Room with Acidification.") I loved this book.

Both Berwald and Staaf excel in weaving a compelling conservation message. They offer a powerful understanding of why jellyfish and cephalopods are proliferating. When slowgrowing, long-lived, tasty species such as cod are fished, trawled, polluted and suffocated out of their habitats, their former ecospace is often filled by opportunistic species with weedy lifestyles. Enter jellyfish and squid.

Both authors focus on ocean acidification as the major driver behind the invertebrate boom. But with its cousin, increasing temperature, acidification is far from the only threat to the marine ecospace. What about destructive and over-extractive fishing, excess nutrients and hypoxia, coastal construction, exotic-species transport, macro- and microplastics, chemical run-off and silting of filtering species such as bivalves and worms? Many organisms experience multiple impacts simultaneously, and synergies mean that the effects may be much worse together than in isolation. Alas, that's another book...

Lisa-ann Gershwin is the author of Stung! and Jellyfish. She studies jellyfish management with the Commonwealth Scientific and Industrial Research Organisation in Hobart, Australia. e-mail:lisa-ann.gershwin@csiro.au 